\title{
Epidemiological, bacteriological profile and bacterial resistance of urinary tract infections at pregnant woman in prenatal consultation in African setting
}

\author{
Koffi Abdoul Koffi ${ }^{1 *}$, Edèle Kacou Aka ${ }^{1}$, Horo Apollinaire ${ }^{1}$, Alice Mlan Britoh ${ }^{2}$, \\ Jean Marie Perel Konan ${ }^{1}$
}

\begin{abstract}
${ }^{1}$ Department of Obstetrics and Gynecology, University Felix Houphouet Boigny, Yopougon University Hospital Abidjan, Côte D'Ivoire

${ }^{2}$ Department of Bacteriology-virology, University Felix Houphouet Boigny, Yopougon University Hospital Abidjan, Côte D'Ivoire
\end{abstract}

Received: 02 December 2019

Accepted: 02 January 2020

\section{*Correspondence:}

Dr. Koffi Abdoul Koffi,

E-mail: kkoffiabdoul@yahoo.fr

Copyright: ( ) the author(s), publisher and licensee Medip Academy. This is an open-access article distributed under the terms of the Creative Commons Attribution Non-Commercial License, which permits unrestricted non-commercial use, distribution, and reproduction in any medium, provided the original work is properly cited.

\begin{abstract}
Background: Urinary tract infection is a common pathology during pregnancy due to hormonal and morphological changes. Objective of this study was to improve management of urinary tract infection during prenatal care.

Methods: A total of 987 pregnant women who have been in prenatal care have freely accepted to participate in crosssectional study carried out from $1^{\text {st }}$ May 2016 to 30 $0^{\text {th }}$ April 2017 at Yopougon University Hospital (Abidjan Côte d'Ivoire) were included. Patients were submitted to questionnaire by one of investigators for epidemiological component and then physical examination was carried out by her attending physician for clinical component. Then at laboratory urine was taken for culture after dipstick test.

Results: Of the 987 patients included $9.4 \%$ had a urinary tract infection of which $81.7 \%$ were asymptomatic. Significant risk factors retained were existence of a history of urinary tract infection $(\mathrm{OR}=0.46 ; \mathrm{p}=0,038)$ and gestational age of pregnancy $(\mathrm{OR}=0.44 ; \mathrm{p}=0.05)$. Urine culture isolated germs were mainly Escherichia Coli $(51.6 \%)$ and Klebsiella pneumoniaie (23.6\%). These germs were all susceptible to cephalosporins. They had resistances of more than $50 \%$ to penicillins.

Conclusions: Escherichia coli and Klebsiella pneumoniae are most common germs of urinary tract infections in pregnant women. Escherichia coli is not susceptible to penicillins with a resistance of $70 \%$ for penicillins except for clavulanic acid amoxicillin. It appears as first choice antibiotic for our prescriptions in case of probabilistic antibiotic therapy.
\end{abstract}

Keywords: Bacterial resistance, Côte d'Ivoire, Pregnancy, Urinary tract infection

\section{INTRODUCTION}

Urinary tract infection (UTI) is a common pathology of women, especially pregnant women, due to hormonal and morphological changes that occur during pregnancy. Frequency is between 5 and $20 \%$ according to various studies carried out around world, and rates observed differ little according to health level of main countries. ${ }^{1-3}$

Although often asymptomatic, association of UTI with pregnancy may progress towards symptomatic bacteuria; acute cystitis, but especially acute pyelonephritis. 
Obstetric consequences are then fatal, low birth weight and very high mortality rates. ${ }^{4,5}$

High prevalence due to morphological causes may also be influenced by some sociodemographic factors and some medical and gynecological histories. ${ }^{3,5} 50 \%$ of women with UTI would have a history of UTI. Other risk factor were high maternal age, multiparity, sexuality, diabetes, immunosuppression, anemia etc. ${ }^{4-6}$

Cytobacteriologic analysis of urine, founded in most cases, enterobacteria and Escherichia coli as main germ of these UTI. ${ }^{4,5}$ In a qualitative way, urine culture are used to determine pathogen involved, to guide therapy and to detect possible therapeutic failures due to presence of resistant. ${ }^{6}$ America Society of infectious disease's Guidelines recommend that uncomplicated UTI should be treated empirically with sulphamethoxazole/trimethoprim (SMX/TMP) up to a resistance rate of 10-20\%, in which case a fluoroquinolon should be used. ${ }^{6,7}$ Resistance of $E$. coli and other Enterobacteriaceae, continued to develop, with a decrease in susceptibility to antibiotics of first line such as Ampicillin, Nitrofurantoin.

Few local data on the bacteriological profile and antibiotic resistance exist in pregnant woman in our daily practice. In our area prescription of antibiotics is done without a laboratory guide, sometimes free sales without a prescription. These facts were presented as one of possible reasons for increase in bacterial resistance to antimicrobial agents. ${ }^{4,5,7}$ Antibiotic therapy for UTI is also empirically and probabilistically initiated. To improve our practices, we carried out this study whose general objective is to contribute effectively to treatment and specifically to determine the most common germs in routine prenatal care and to specify their level of resistance and susceptibility to antibiotics.

\section{METHODS}

We conducted a cross-sectional, descriptive and analytical study over a 12-month period from May 01, 2016 to April 30, 2017 at Yopougon University Hospital in consultation unit of gynecology-obstetrics and at central laboratory (unit of bacteriology virology).

\section{Inclusion criteria}

- This was any pregnant woman received in prenatal care regardless of gestational age and without urine culture carried out beforehand having given their free and informed consent.

\section{Exclusion criteria}

- Patients with an antibiotic treatment in progress or less than two weeks old, those not complying with the conditions of urinary withdrawal and those not the urine were contaminated were excluded.
A study carried out in Côte d'ivoire in Abidjan by Loc'h in 2014 showed a prevalence of UTI in prenatal consultation, which was $4,9 \% .^{8}$ By considering a maximum prevalence (p) of $10 \%$ with a risk of 1 st species $\alpha=5 \%$, at least 138 pregnant women were to be recluse. For our study, sample size (n) was calculated to power analysis with $\mathrm{n}=1,962 \times 0,1(1-0,1) / 0,052=138$ $(\mathrm{Z}=1,96, \alpha=5 \%, \mathrm{p}=10 \%)$.

During study year, consulting service registered 9613 women whose $5580(57 \%)$ for prenatal consultations. As well 987 were collected and was the sample of our study.

Data collection and analysis: We collected different data on questionnaire standardized by two investigators (gynecologist doctor, laboratory technician). Results are presented in the form of tables and graphs using EPI Info 7 version 11.0 and Excel software. Comparison of proportions was carried out with statistical tests Chi-2 and $\mathrm{T}$ student.

Sociodemographic data, history of pregnancy and urinary tract infection, clinical signs, rate of nitrites and leukocytes in urine strips test, and urine culture (resistance of bacteria and susceptibility to antibiotics) have been analyzed.

\section{Conduct of study}

Classic obstetric examination is made which can also be used to search for risk factors or signs of infection. Patient is admitted then to the lab. Urine Collection is done in a sterile pot after disinfection of the vulva at the Betadine Solution ${ }^{\circledR}$ Gynecological. Urine collection technique used was that of the Mi-jet. In laboratory a part of sample was used for urine dipstick test and other part culture. Reading of urine strips is carried out by technician of the day and listed by the investigator on the questionnaire. Once test at strip is positive, a crop with germ identification and a sensitivity is carried out in the 24 hours to 48 hours.

\section{RESULTS}

Table 1: Diagnostic aspect of urinary tract infection.

\begin{tabular}{|ll|}
\hline Diagnosis & Number (\%) \\
\hline No UTI & $894(90.6)$ \\
\hline Asymptomatic bacteria & $76(7.7)$ \\
\hline Cystitis & $17(1.7)$ \\
\hline Total & $\mathbf{9 8 7}(\mathbf{1 0 0})$ \\
\hline Isolated germs & \\
\hline Escherichia coli & $48(51.6)$ \\
\hline Enterobacter sp. & $5(.3)$ \\
\hline Klebsiella pneumoniae & $22(23.6)$ \\
\hline Staphylococcus coagulase & $7(7.5)$ \\
\hline Staphylococcus aureus & $9(9.6)$ \\
\hline Total & $\mathbf{9 3}(\mathbf{1 0 0})$ \\
\hline
\end{tabular}


Table 2: Risk factors of UTI in pregnant woman $(\mathbf{n}=93)$.

\begin{tabular}{|c|c|c|c|c|}
\hline \multicolumn{2}{|c|}{$\begin{array}{l}\text { Epidemiological } \\
\text { clinic factors }\end{array}$} & UTI, $\mathbf{N}(\%)$ & $\begin{array}{l}\text { Odds } \\
\text { ratio }\end{array}$ & p-value \\
\hline \multirow{5}{*}{ Age } & $<25$ & $217(6.9)$ & & \\
\hline & $25-30$ & $309(11.3)$ & 0.581 & 0.089 \\
\hline & $30-34$ & $266(9.4)$ & 0.715 & 0.324 \\
\hline & $35-39$ & $165(9.1)$ & 0.742 & 0.433 \\
\hline & $\geq 40$ & $3(8.6)$ & 0.866 & 0.827 \\
\hline \multirow{2}{*}{ Literate } & Yes & $74(9.7)$ & 1.188 & 0.521 \\
\hline & No & $19(8.3)$ & & \\
\hline \multicolumn{5}{|c|}{ Professional activity } \\
\hline \multicolumn{2}{|c|}{ Yes } & $68(9.1)$ & 0.882 & 0.611 \\
\hline \multicolumn{2}{|l|}{ No } & $25(10.2)$ & & \\
\hline \multicolumn{5}{|c|}{ Marital status } \\
\hline \multicolumn{2}{|c|}{ Single woman } & $27(9.7)$ & 0.954 & 0.845 \\
\hline \multicolumn{2}{|c|}{ Married } & $66(9.3)$ & & \\
\hline \multicolumn{5}{|c|}{ Gestational age } \\
\hline \multicolumn{2}{|c|}{$1^{\text {st }}$ trimester } & $6(4.8)$ & 0.44 & 0.05 \\
\hline \multicolumn{2}{|c|}{$2^{\text {nd }} \cdot 3^{\text {rd }}$ trimester } & $87(10.1)$ & & \\
\hline \multicolumn{5}{|c|}{ Parity } \\
\hline \multicolumn{2}{|l|}{0} & $25(7.6)$ & 0.713 & 0.165 \\
\hline \multicolumn{2}{|l|}{$\geq 1$} & $68(10.3)$ & & \\
\hline \multicolumn{5}{|c|}{ History of UTI } \\
\hline \multicolumn{2}{|l|}{ Yes } & $9(0.46)$ & 0.460 & 0.038 \\
\hline \multicolumn{2}{|l|}{ No } & $84(9.0)$ & & \\
\hline \multicolumn{5}{|c|}{ Vaginitis } \\
\hline \multicolumn{2}{|c|}{ Yes } & $17(11.1)$ & 1.24 & 0.436 \\
\hline \multicolumn{2}{|l|}{ No } & $76(9.9)$ & & \\
\hline
\end{tabular}

Means age of patients was 30.8 years $(\sigma=4.7$ years and IC $1-\alpha=30.51-31.08)$ with extremes of 16 and 45 years. Most important age group (30.2\%) was 25 to 29 years. Majority of patients $(32.3 \%)$ were nulliparous.

Prevalence of urinary tract infections is $8.8 \%$. It was asymptomatic bacteriuria and acute cystitis. Escherichia coli, Klebsiella pneumonia were most isolated germ after urinary culture in laboratory. Their cumuled rate was $74 \%$.

Table 1 presents clinical forms and isolated germs. For factors associated with UTI, Significant risk factors retained were existence of a history of urinary tract infection $(\mathrm{OR}=0.46 ; \mathrm{p}=0,038)$ and gestational age of pregnancy $(\mathrm{OR}=0.44 ; \mathrm{p}=0.05)$. Table 2 reports epidemiological aspects.

Susceptibility of germs such as Escherichia coli, Klebsiella pneumoniaie, Enterobacter sp., Staphylococcus $s p$. have been tested. E coli had resistance against amocillin at 71\%, Klebsiella sp. 100\%, amoxicilin+ clavulanic acid at $33 \%$.

These germs were all susceptible to cephalosporins but they had resistances of more than $50 \%$ to penicillins. Resistance to monobactam, carbapenem are lower; zero to $23 \%$. Table III sets out susceptibility of germs to antibiotics.

Table 3: Bacterial strains resistance in antibiotics.

\begin{tabular}{|c|c|c|c|c|c|c|c|}
\hline \multicolumn{2}{|c|}{ Antibiotic } & & $\begin{array}{l}\text { E. coli } \\
* \mathbf{r}(\%)\end{array}$ & $\begin{array}{l}\text { Klebsiella } \\
*_{\mathbf{r}}(\%)\end{array}$ & $\begin{array}{l}\text { Enterobacter } \\
\text { Sp. *r }(\%)\end{array}$ & $\begin{array}{l}\text { Staphylococcus } \\
\text { coagulase } \\
* \mathbf{r}(\%)\end{array}$ & $\begin{array}{l}\text { Staphylococcus } \\
\text { aureus } \\
* \mathbf{r}(\%)\end{array}$ \\
\hline \multirow{4}{*}{\multicolumn{2}{|c|}{ Penicillin }} & Amoxicillin & 70.9 & 100 & 100 & 100 & 100 \\
\hline & & $\begin{array}{l}\text { Amoxicillin } \\
\text { Ac clavulanic }\end{array}$ & $(33.3)$ & (23) & $(100)$ & 43 & 33 \\
\hline & & Ticarcillin & $(100)$ & $(100)$ & $(100)$ & 100 & 100 \\
\hline & & Piperacillin & $(100)$ & $(100)$ & $(100)$ & 100 & 100 \\
\hline \multirow{6}{*}{ Cephalosporin } & $\begin{array}{l}1^{\text {st }} \\
\text { generation }\end{array}$ & Cefalotin & (47) & (0) & $(40)$ & 28 & 22 \\
\hline & $\begin{array}{l}2^{\text {nd }} \\
\text { generation }\end{array}$ & Cefuroxim & (43) & $(0)$ & $(40)$ & 28 & 22 \\
\hline & \multirow{4}{*}{$\begin{array}{l}3^{\text {rd }} \\
\text { generation }\end{array}$} & Ceftriaxon & $(35)$ & $(0)$ & (20) & 14 & 0 \\
\hline & & Ceftazidim & (31) & (0) & (20) & 14 & 0 \\
\hline & & Cefixim & (37) & (0) & (20) & 14 & 0 \\
\hline & & Cefepim & (31) & (0) & (20) & 0 & 0 \\
\hline \multicolumn{2}{|l|}{ Monobactam } & Aztreonam & (23) & (0) & (0) & 0 & 0 \\
\hline \multicolumn{2}{|l|}{ Carbapenem } & Imipenem & (9) & $(0)$ & $(0)$ & 0 & 0 \\
\hline
\end{tabular}

$*_{\mathrm{r}}(\%)=$ bacterial resistance.

\section{DISCUSSION}

Several factors have been identified as associated with UTI in pregnant women. These include multiparty, gestational age, previous history of UTI, diabetes mellitus, and anatomical abnormalities in the urinary tract. ${ }^{9-11}$ Also, some authors noted that maternal anemia, low socioeconomic, educational level, sexual intercourse 
are also associated with UTI. ${ }^{2,12,14}$ Other factors had not retained in our study because of many missing data for various reasons also have an association on UTI.

\section{Risk factors}

Socio-demographic aspects: following sociodemographic factors: age, profession, and level of study, a had no significant association with UTI. Several authors including Morike, Masinde, Emiru mentioned this lack of association. $^{1,9,14}$ In fact, socio-economic level has been assimilated in our study to schooling or to exercise of a professional activity with regular incomes. According to our results, there is no statistically significant difference whether it is in school or not $(\mathrm{p}=0.52)$, or whether it is monthly or non-income $(\mathrm{p}=0.611)$. Thus, low socioeconomic level would not favour occurrence of a ABU as some authors. ${ }^{15,16}$

According to some researchers, age had a significant influence on prevalence of asymptomatic bacteriuria. ${ }^{1,15,16}$ Thus, age group 26-30 years had highest percentage of infection $(53.1 \%)$, followed by age group 36-40 (52.5\%) and $31-35(52.1 \%)$ with $\mathrm{p}<0.0001 .{ }^{17}$ Admittedly, prevalence was significantly higher with age in our study but without any significant difference. This could be justified by that advanced maternal age ( $\geq 35$ years) was reported as a risk factor for ABU during pregnancy..$^{10,17}$ Other factor can justify this, is multiparity. It is considered a risk factor for the occurrence of ABU. ${ }^{18}$

UTI in pregnant women could therefore be met at any age, regardless of occupation, and level of study without much difference.

Sexuals intercourse were also described as another risk factor. In women anatomical relationship of female urethra to vagina makes it prone to trauma during sexual intercourse. Bacteria can also be massed at meatus urethral during sexual act and colonize secondarily urinary tract. ${ }^{19}$

Among sexually active young women, incidence of UTI is high, and risk is strongly and independently associated with recent sexual intercourse, recent use of a diaphragm with spermicide, and a history of recurrent UTI. He is same for Haider and $\mathrm{Al}$ in Pakistan and Amiri among pregnant women in Iran. ${ }^{20,21}$

\section{Clinical aspects}

In our study, only history of UTI $(\mathrm{OR}=0.46 ; \mathrm{p}=0,038)$ and gestational age $(\mathrm{OR}=1.83 ; \mathrm{p}=0.05)$ had $\mathrm{a}$ significant association with presence of UTI. A previous episode of UTI predisposes to a new infection. This same observation was made by other authors; Emiru in Ethiopia, Haider in Pakistan, Taher in Qatar, Sescon in the Philippines, Kovavisarach in Thailand, and Masinde in Tanzania. ${ }^{9,14,21,23,25}$ Hamdan et al, in Sudan reported a strong association with UTI $(\mathrm{p}=0.0001 ; \mathrm{OR}=3,397, \mathrm{CI}$ $=1,672,6,902) .^{2}$

For pregnancy, peak-period of infection was second and third trimesters. In Nigeria, they also founded a higher incidence of urinary tract infection in third trimester of pregnancy. ${ }^{25}$ This could be explained by urinary stasis. Major cause of UTI was increased in the third trimester with greater compression of the bladder and ureters by the uterus pregnant. However, other studies reported opposite results, notably Masinde and Emiru, which found higher prevalence in first trimester., ${ }^{9,14}$

There was no significant difference in prevalence of urinary infection in relation to term of pregnancy according to Hamdan et al, Masinde et al. ${ }^{2,14}$ These divergent results could be biased due to absence of a detailed analysis of distribution of risk factors by gestational age in their study.

Apart from these factors, statistical analysis reveals many pregnancies was not an associated factor. However, multiparity has been identified as a risk for UTI in pregnant women by some authors. ${ }^{5,24,26,27}$ Although, analysis of association between parity and UTI was not statistically significant in our study $(P=0.165)$. Many parities increased prevalence of UTI. This association may be due to physiological changes affecting urinary tract during pregnancy, including a sluggishness of ureters. It would therefore explain recurrence of UTI in multiparous. However, Moyo in Tanzania and Emiru in Ethiopia have reported a lack of significant association between urinary infection and many pregnancies. ${ }^{9,27}$ For many pregnancies there was an abortion. In such case, pre-term pregnancy does not have significant physiological changes in urinary tract.

At literature review other risk factors have been reported such as intercurrent pathologies, maternal anemia. It was significantly associated with urinary infection for some researchers, whether in Qatar, Pakistan, Iran or the Philippines. ${ }^{23,28,29}$ For these women frequent etiology of anemia in their region are martial deficiency linked to a food defect, infectious diseases and consequence of a decrease in immunity.

In addition, uterine fibroids exposed to recurrence of UTI. Langer in Israel had shown that they have a repercussion on urinary tract. ${ }^{29}$ Sluggishness of ureters and urinary stasis observed during pregnancy have been aggravated by existence of uterine fibroids. This explains higher prevalence of UTI in women with uterine fibroids.

Also, prevalence of urinary tract infection in women with vaginitis was higher but no significant difference ( $\mathrm{p}=$ 0.436) in those with no vaginitis. Amatya and Demilie showed a strong association vaginitis and UTI. ${ }^{30,31}$ This could be explained by proximity of uretra and vagina, and a decrease in local immunity to promote microbial growth. 
Differences in results of risk factors in many studies may be due to differences in the methodology, population characteristics (Standard of living) and size of sample.

\section{Bacteriological profile}

Urine culture isolates a germ in $50 \%$ of cases. ${ }^{32}$ Nature of germs isolated from urine culture varies depending on location and form of infection (acute, recurrent or induced). Escherichia coli represents 60 to $70 \%$ of the isolated germs in city practice, remainder is represented by Gram-negative bacilli (Proteus mirabilis, Klebsiella Pneumonae, Enterobacter) and positive Cocci gram. ${ }^{33}$

Enterobacteria and in particular Escherichia coli are most frequently encountered. Germs are the same as outside pregnancy, but generally more varied: Escherichia coli (85\% of infections out of hospital), Staphylococcus saprophyticus (5-15\%), Gardnerella, Chlamydia, Klebsiella, Proteus, Pseudomonas, Enterococcus (510\%), sometimes Uréaplasma and Lactobacillus, with uncertain meaning. ${ }^{33,34}$ It could be argued that E. coli remains the first isolated germ in UTI in the world, particularly in West Africa. ${ }^{3,33}$ E. coli is part of flora of digestive tract. Proximity of vagina, meat urethral and anus, entrains a rapid colonization of urinary tract. ${ }^{7}$

Our research have found Gram negative bacilli (E. coli; $51.6 \%$ ) followed by Klebsiella Pnemoniae (23.6\%). It was same in urine culture of pregnant women seen in Turkey and Moyo in Tanzania. ${ }^{27}$ At Cameroon, Morike implicated Gram-negative bacilli as germs responsible for UTI at prenatal care. ${ }^{1}$ Others, Hamdan in Sudan noted both Gram negative and positive bacilli but with a predominance of Gram-negative bacilli. ${ }^{2}$ In pregnant women as in most community UTI, Gram-negative bacilli remain most found. ${ }^{26}$

Klebsiella Pneumonae was second, reported also by other authors. ${ }^{1,34,35}$ However Loc'h, in Côte d'ivoire and Rajaratnam in India in noted as the majority germ Klebsiella Pneumoniae followed by Escherichia coli. ${ }^{8,35}$

\section{Antibiotic susceptibility}

Different germs isolated were subsequently tested for susceptibility to different antibiotics. Antimicrobial resistance in uropathogens is becoming increasingly common due to availability, limited choice and wide use of antibiotics. ${ }^{11,12,36}$ In our study, sensitivity revealed that Escherichia coli showed resistances of $70 \%$ for penicillins except for clavulanic acid amoxicillin $(33.3 \%)$. However, all strains were poorly resistant to $3^{\text {rd }}$ generation cephalosporins (35\%), monobactams (23\%), and carbapenems (9\%). These high resistances to penicillins are found by Onoh in Nigeria. ${ }^{36}$

All strains of Klebsiella pneumoniae isolated were resistant to penicillins except clavulanic acid amoxicillin. However, they were all susceptible to cephalosporins, carbapenems and Monobactams. Loch in Côte d'ivoire and other authors already demonstrated since that isolated Klebsiella pneumoniae strains had higher resistance to penicillins than to other antibiotic families. ${ }^{7,8,13}$ Isolated Enterobacter strains were also resistant to penicillins.

This common resistance to penicillins of Enterobacteria would be due to existence of certain strains of bacteria producing beta-lactamases by these bacteria. Among penicillins, Clavulanic acid amoxicillin was antibiotic that had a better sensitivity because of probably clavulanic acid that has inhibitory activity on betalactamases. ${ }^{6,37}$ For Cephalosporins, Carbapenems, and monobactams, resistance rates remained relatively low. Aminoglycosides and quinolones retain good efficacy on Enterobacteria as reported by some authors. ${ }^{4,37,38}$ Use of carbapenems and monobactams remains limited because they are antibiotics of last resort.

Currently recommended first-line treatment in the treatment of UTI is fosfomycin, as it has advantage of having no cross-resistance mechanism with other antibiotic families. Fluoroquinolones, third-generation cephalosporins, and aminoglycosides retain excellent activity on $E$. coli isolated from community UTI in women aged 15 to 65 years. Global sensitivity rates for $\mathrm{E}$. coli are $61 \%$ for amoxicillin (AMX), $93 \%$ for nalidixic acid (NAL), $97 \%$ for Norfloxacin (NOR) and ciprofloxacin (CIP), $77 \%$ for Cotrimoxazole (SXT), 99\% for Fosfomycin, gentamicin and Cefotaxime. ${ }^{2}$

Antibiotic during pregnancy are restricted by the possible teratogenic effect of certain antibiotics, but data are lacking and no randomized studies can be reasonably implemented. Some choices are based on data extracted from general population. Recent guilines issued by Infectiology Committee of French Urology Association (CIAFU) and French Agency for Health Products Safety (AFSSAPS) have codified management of these pathologies by specifying indications and duration of antibiotic treatment as well as usable molecules and their dosage. ${ }^{12,38,39}$ It is therefore important to set up microbiological monitoring and especially monitoring of antibiotic resistance.

\section{CONCLUSION}

Escherichia coli and Klebsiella pneumoniae are most common germs of urinary tract infections in pregnant women. Escherichia coli is not susceptible to penicillins with a resistance of $70 \%$ for penicillins except for clavulanic acid amoxicillin. It appears as first choice antibiotic for our prescriptions in case of probabilistic antibiotic therapy.

\section{Funding: No funding sources} Conflict of interest: None declared

Ethical approval: The study was approved by the Institutional Ethics Committee 


\section{REFERENCES}

1. Morike NM, Atashili J, Ekane GEH, Ikomey GM, Ndumbe PM, Conly J. Bacteriuria amongst pregnant women in the Buea Health District, Cameroun: prevalence, predictors, antibiotic susceptibility patterns and diagnosis. PLoS One. 2013;8(8):e71086.

2. Hamdan ZH, Ziad AHM, Salah KA, Ishag A. Epidemiology of urinary tract infections and antibiotics sensitivity among pregnant women at Khartoum North Hospital. Ann Clin Microbiol Antimicrob. 2011;10:2.

3. Tadesse E, Teshome M, Merid Y, Kibret B, Shimelis T. Asymptomatic urinary tract infection among pregnant women attending the antenatal clinic of Hawassa Referral Hospital, Southern Ethiopia. BMC Res Notes. 2014;7(1):155.

4. Szweda H, Jóźwik M. Urinary tract infections during pregnancy an updated overview. Develop Period Med. 2016;20(2):463.

5. Oladeinde BH, Omoregie R, Oladeinde OB. Asymptomatic urinary tract infection among pregnant women receiving ante-natal care in a traditional birth home in Benin city, Nigeria. Ethiop J Health Sci. 2015;25(1):3-8.

6. Manjula NG, Math GC, Patil SA, Gaddad SM, Shivannavar CT. Incidence of urinary tract infections and its aetiological agents among pregnant women in Karnataka Region. Adv Microbiol. 2013;3:473-8.

7. Zhanel GG, Hisanaga TL, Laing NM, DeCorby MR, Nichol KA, Palatnick LP, et al. Antibiotic resistance in outpatient urinary isolates: final results from the North American Urinary Tract Infection. Int J Antimicrob Agents. 2005;26:380-8.

8. Le Loc'h. JP. Study of prevalence and microbiological profile of urinary tract infections in pregnant women presenting for prenatal consultation in the health centers of Abidjan, Ivory Coast. University of Bordeaux institute of public health, epidemiology, development. Available at: https://docplayer.fr/6081720-Universite-de-

bordeaux-institut-de-sante-publique-epide.

9. Emiru T, Beyene G, Tsegaye W, Melaku S. Associated risk factors of urinary tract infection among pregnant women at Felege Hiwot Referral Hospital, Bahir Dar, North West Ethiopia. BMC Res Notes. 2013;6:292.

10. Vettore MV, Dias M, Vettore MV. Assessment of urinary infection management during prenatal care in pregnant women attending public health care units in the city of Rio de Janerio, Brazil. Rev Bras Epidemiol. 2013;16(2):338-51.

11. Meher R, Fatima K, Indu S. Rising prevalence of antimicrobial resistance in urinary tract infections during pregnancy: necessity for exploring newer treatment options. J Labophysicians. 2011;3(2):98103.

12. Sibi G, Kamari P, Kabungulundabungi N. Antibiotic sensibility pattern from pregnant women with urinary tract infections in Bangalor, India. Asian Pac J Trop Med. 2014;7S1:S116-20.

13. Kladensky J. Urinary tract infections in pregnancy: when to treat, how to treat and what to treat with. Ceska Gynekol. 2012;77(2):167-71.

14. Masinde A, Gumodoka B, Kilonzo A, Mshana S. Prevalence of urinary tract infection among pregnant women at Bugnado Medical Centre, Mwanza, Tanzania. Tanzan J Health Res. 2009;11(3):154-9.

15. Turpin CA, Minkah B, Danso KA. Asymptomatic Bacteriuria in pregnant women attending antenatal clinic at Komfo Anokye teaching hospital, Kumasi, Ghana. Ghana Med J. 2007;41:26-9.

16. Amadi ES, Enemuo OB, Uneke CJ, Nwosu OK, Onyeagba RA, Ugbogu OC. Asymptomatic bacteriuria among pregnant women in Abakaliki, Ebonyi State, Nigeria. J Med Sci. 2007;7(4):698700 .

17. Imade PE, Izekor PE, Ophori E. Asymptomatic bacteriuria among pregnant women. North AmJ Med Sci. 2010;2(6):263-6.

18. Fatima N, Ishrat S. Frequency and risk factors of asymptomatic bacteriuria during pregnancy. J Coll Physicians Surg Pak. 2006;16:273-5.

19. Okonko IO, Ijandipe LA, Ilusanya OA. Incidence of urinary tract infection (UTI) among Pregnant women in Ibadan, South-Western Nigeria. Afr J Biotechnol. 2009;8:6649-57.

20. Haider G, Zehra N, Munir AA, Haider A. Risk factors of urinary tract infection in pregnancy. J Pak Med Assoc. 2010;60:213-6.

21. Amiri FN, Rooshan MH, Ahmady MH. Hygiene practices and sexual activity associated with urinary tract infection in pregnant women. East Mediterr Health. 2009; 15:104-10.

22. Taher MA, Al-Meer FM, Al-Kuwari MG. Prevalence and predictors of asymptomatic bacteriuria among pregnant women attending primary health care in Qatar. Middle East J Fam Med. 2009;7:10-3.

23. Sescon NIC, Garingalao-Molina FD, Ycasiano CEJ. Prevalence of asymptomatic bacteriuria and associated risk factors in pregnant women. Phil J Microbiol Infect Dis. 2003;32:63-9.

24. Kovavisarach E, Vichaipruck M, Kanjarahareutai S. Risk factors related to asymptomatic bacteriuria in pregnant women. J Med Assoc Thai. 2009;92:60610.

25. Oli AN, Okafor CI, Ibezim EC, Akujiobi CN, Onwunzo MC. The prevalence and bacteriology of asymptomatic bacteriuria among antenatal patients in Nnamdi Azikiwe University Teaching Hospital Nnewi; South Eastern Nigeria. Niger J Clin Pract. 2010;13(4):409-12.

26. Cram LF, Zapata MI, Toy EC. Genitourinary infections and their association with preterm labor. Am Fam Physician. 2002;65(2):241-8.

27. Moyo SJ, Aboud S, Kasubi M, Maselle SY. Bacterial isolates and drug susceptibility patterns of urinary tract infection among pregnant women at Muhimbili 
National Hospital in Tanzania. Tanzan J Health Res. 2010;12(4):236-40.

28. Hooton TM, Schools D, Hughes JP. Prospective study of risk factors for symptomatic urinary tract infection in young women. $\mathrm{N}$ Engl $\mathrm{J}$ Med. 1996;335:468-74.

29. Langer R, Golan A, Neuman M, Schneider D, Bukovsky I, Caspi E. The effect of large uterine fibroids on urinary bladder function and symptoms. Am J Obstet Gynecol. 1990;163(4 Pt 1):1139-41.

30. Amatya R. Urinary tract infection in vaginitis: a condition often overlooked. Nepal Med Coll J. 2013;15(1):65-7.

31. Demilie T, Beyene G, Melaku S, Tsegaye W. Diagnostic accuracy of rapid urine dipstick test to predict urinary tract infection among pregnant women in Felege Hiwot Referral Hospital, Bahir Dar, North West Ethiopia. BMC Res Notes. 2014;7:481.

32. Tagajdid MR, Boumhil L, Iken M, Adnaoui M, Benouda A. Study of resistance of Escherichia Coli strains isolated in urine to third generation fluoroquinolones and cephalosporins. Med Et Mal Infect. 2010;40(2):70-3.

33. Alemu A, Feleke M, Yitayal S, Ketema T, Kassu A, Anagaw B. Bacterial profile and drug susceptibility pattern of urinary tract infection in pregnant women at university of Gondar teaching hospital, northwest Ethiopia. BMC Res Notes. 2012;5:197.

34. Unlu BS, Yildiz Y, Keles I, Kaba M, Kara H, Tasin C. Urinary tract infection in pregnant population, which empirical antimicrobial agent should be specified in each of the three trimesters? Ginekol Pol. 2014;85(5):371-6.

35. Rajaratnam A, Neha MB, Kuruvilla TS, Machado S. Diagnosis of asymptomatic bacteriuria and associated risk factors among pregnant women in Mangalore, Karnataka, India. J Clin Diagn Res. 2014;8(9):23-5.

36. Onoh RC, Egwuatu VE, Onoh TJP. Antibiotic sensitivity pattern of uropathogens from pregnant women with urinary tract infection in abakaliki, Nigeria. Infect Drug Resist. 2013;6:225-33.

37. Dinh A, Baumann R, Daou S, Salomon J, Bruyère F, Bernard L. Règles de prescriptions des antibiotiques à visée urologique chez la femme enceinte. Progrès en Urologie-FMC. 2009;19(4):F118-22.

38. Vettore MV, Dias M, Vettore MV. Assessment of urinary infection management during prenatal care in pregnant women attending public health care units in... Rev Bras Epidemiol. 2013;16(2):338-51.

39. Rizvi M, Khan F, Shukla I, Malik A. Rising prevalence of antimicrobial resistance in urinary tract infections during pregnancy: necessity for exploring newer treatment options. J Lab Physicians. 2011;3(2):98.

Cite this article as: Koffi KA, Aka EK, Apollinaire H, Mlan-Britoh A, Konan JMP. Epidemiological, bacteriological profile and bacterial resistance of urinary tract infections at pregnant woman in prenatal consultation in African setting. Int J Reprod Contracept Obstet Gynecol 2020;9:461-7. 